\title{
JAPANESE ACTIVITIES IN REFRIGERATION TECHNOLOGY
}

\author{
T. Fujita, T. Ohtsuka and Y. Ishizaki * \\ Department of Physics, Tohoku University, Sendai 980, Japan
}

\section{$\underline{\text { ABSTRACT }}$}

This paper reviews recent activities in refrigeration technology in Japan, which are stimulated strongly by growing induxtirial demands and big national projects. At present, the JNR project on the MAGLEV train is the most powerful one and requires all knowledges of cryogenics including various scales of refrigeration. In fact, several $R$ \& $D$ works are now in progress for various types of refrigerators. Currently research activities have also started in developing Stirling cycle refrigerators and magnetic refrigerators for applications in a wider area.

\section{INTRODUCTION}

Research in the field of cryogenic refrigeration below $20 \mathrm{~K}$ in Japan was initiated at Tohoku University as a study of low temperature physics. Besides the accumulation of basic physical data, some effort was also made to construct helium liquefiers in this early period of study. However, the first helium liquefier in Japan was an imported ADL Collins machine, which was installed at Tohoku University in 1952. Following Tohoku University, some other univeristies, national laboratories and companies installed the same type of helium liquefiers successively during the next decade. In 1958, a group at the Institute for Solid State Physics, the University of Tokyo, succeeded in producing liquid helium by the first Japanese liquefier of cascade type with an output of 4 liters per hour. Helium liquefiers in this period were used mainly for laboratory experiments. Industrial needs for larger machines have grown up in conjunction with progress in superconducting magnet technology and its applications.

As for cryocoolers, the Gifford-McMahon cycle was first investigated at Hitachi Ltd. The first test machine was reported to operate successfully but it was not directly followed by a practical machine. A recent application of the Gifford-McMahon refrigerator will be described by Matsubara and Yasukochi in this Conference [1]. Supported by the group in the University of Tokyo, Osaka Oxygen Industries developed a small cryocooler of a modified Solvay cycle in 1971. A commercial version of this machine "Cryo-mini" is now

* Technical Consultant. 
available with a capacity of $1 \mathrm{~W}$ at $15 \mathrm{~K}$, being applied mainly for cryopumps. Basic study of Stirling cycle cryocooler was carried out at the University of Tokyo and $30 \mathrm{~K}$ was reached in 1972 [2]. An improved version of this test machine will be discussed later.

Recent activities in refrigeration technology in Japan are strongly stimulated by big national projects. Of such stimulants, the Japanese National Railways (JNR) project on the superconducting magnetically levitated (MAGLEV) vehicles is the most powerfull one at present. As part of the project, $R \& D$ works are now in progress for various types of on-board refrigerators including Claude cycle, Stirling cycle and Gifford-McMahon cycle machines. Some of them are expected to meet general demands for applications in a wider area, such as for cryopumps. Superconductive electronics also is one of the recent $R$ \& $D$ targets in Japan which require cryogenic environment. However there have been practically no activities in developing small, low-noise cryocoolers for this purpose. As a rare exception. the present authors have just started to develop small Stirling cycle cryocoolers for high temperature SQUIDs. Research activities have also started in developing magnetic refrigerators. In the following, the current activities are reviewed on development of such cryocoolers which produce low temperatures particularly below $20 \mathrm{~K}$.

\section{MAGLEV REFRIGERATION SYSTEM}

The JNR MAGLEV project was initiated formally in 1970 following technical, economical and environmental assessments. After a variety of laboratory tests, the first running test by a $1 / 2$ scale model vehicle ML500 was conducted in 1977 , using the $1.3 \mathrm{~km}$ section of guideway constructed in Miyazaki prefecture. At this early stage of running tests, a sealed-off cryostat system for superconducting magnets was employed [3]. In parallel, research was also made on developing small scale "on-board" refrigerators. In 1978, an on-board refrigerator with a capacity of $30 \mathrm{~W}$ at $4.4 \mathrm{~K}$ was installed on ML500R and tested at $200 \mathrm{~km} / \mathrm{hr}$. A series of tests with ML500 were successfully completed in 1979 with achievement of a record speed of $517 \mathrm{~km} / \mathrm{hr}$ on the $7 \mathrm{~km}$ full scale test track in Miyazaki [4].

For performance tests on more practical vehicles containing all essential feature required commercially, the test track was converted in 1980 from the inverted $\mathrm{T}$-shape to a U-shaped guideway (Fig. 1). In parallel, a test train MLU001 was constructed. As shown in fig. 2, the final configuration of the new model consists of three connected vehicles, each of which has eight superconducting magnets. Figure 3 shows the arrangement of compressors, refrigerators, cryostats, and superconductive magnets. Two superconducting magnets are installed in one cryostat on the first and third cars (MLU001-1 and -3), whereas each magnet is installed individually in one cryostat on the second car (MLU001-2). To compensate for heat leak to cryostats, one refrigerator per car system is employed on MLU001-1, but one refrigerator per cryostat system is employed on MLU001-2 and -3 . The configuration is expected to allow critical comparison between various systems. 
A remarkable progress has been made in cryostat design during the past ten years. Finally, a cooling capacity of $2.5 \mathrm{~W}$ per magnet was specified for the cryocooler to compensate the heat leak. JNR is developing various onboard refrigerators in collaboration mainly with three industrial groups: Hitachi Ltd., Toshiba Co./ Sumitomo Heavy Industries Ltd., and Mitsubishi Electric Co./ Aisin Seiki Co.

Figure 4 shows a Claude cycle refrigerator of type A with a capacity of $30 \mathrm{~W}$ at $4.4 \mathrm{~K}$ developed for MLU001-1. Specifications of the machine are listed in the Table 1. The machine has 5 stages of heat exchangers, 2 expansion engines and a Joule-Thomson valve.

Claude cycle refrigerators of type $B$ with a capacity of $5 \mathrm{~W}$ at $4.5 \mathrm{~K}$ were independently developed and installed on MLU001-2 and -3 . Figure 5 shows one of the machines attached on the cryostat. The heat exchangers which were adopted for this type of refrigerators will be described by Koizumi et al. in this Conference [5].

An on-board refrigerator of type $C$ which consists of Stirling cycle and Joul-Thomson loop, was also developed for MLU001-2. The J-T loop has four heat exchangers, three precoolers and a $\mathrm{J}-\mathrm{T}$ valve. Each stage of the precoolers is cooled by a three stage Stirling cycle refrigerator, which is operated at $4.93 \mathrm{~Hz}$ with helium gas pressure of $16 \mathrm{~kg} / \mathrm{cm}^{2}$. The coldest stage of the refrigerator reached $11.1 \mathrm{~K}$. The overall cooling capacity of this machine is $8 \mathrm{~W}$ at $4.37 \mathrm{~K}$. Further effort is concentrated on developing a Sti ${ }^{\sim}$ ing cycle machine which can reach $4 \mathrm{~K}$ without $\mathrm{J}-\mathrm{T}$ loop.

In November of 1982, JMR succeeded in the manned test run with three connected cars train MLU001 which carries these various types of refrigerators.

\section{OTHER DEVELOPMENTS}

\section{STIRLING CYCLE CRYOCOOLER}

After basic investigation on regenerators and refrigeration cycles, Ishizaki and his co-workers at the University of Tokyo designed some Stirling cycle cryocoolers in the early 1970s. A three-phase Stirling cycle machine was constructed to obtain optimal design figures. Especially the effect of phase angle on refrigeration output was investigated with different compression and expansion volume ratios. Based on the result, they next constructed a four-phase Stirling cycle cryocooler, in which the pistons were driven with a swash plate. This machine produced a refrigeration output of $45 \mathrm{~W}$ at $78 \mathrm{~K}$ [2]. A four-phase regenerator, which consists of multi-layers of metal plate fixed with adhesives and small metal balls inside was also developed for compact design and improvement in thermal efficiency.

More recently, Ishizaki cooperated with a group of Aisin Seiki in developing a commercial Stirling cycle cryocooler. Figure 6 shows the 2 stage Stirling cycle cryocooler developed for general purposes including application 
to cryopumps. A swash plate driving mechanism is employed to convert motor rotation to reciprocal motions of four pistons which are arranged at 90 degree intervals. A pair of the counter pistons is for the second stage of $20 \mathrm{~K}$ cooling circuit, whereas the other pair is for the first stage of $90 \mathrm{~K}$ cooling circuit which is used to precool the 2nd stage. Cooling capacities of $20 \mathrm{~W}$ and $150 \mathrm{~W}$ are reported at the first stage temperature of $90 \mathrm{~K}$ respectively with cooling down time of about 15 minutes.

A low noise Stirling cycle cryocooler is also investigated for cooling SQUID sensors. Recently, we developed $\mathrm{Nb}_{3} \mathrm{Ge}$ SQUIDs which operate satisfactorily at temperatures approaching $18 \mathrm{~K}$ [6]. Our device has a relatively wide range of operating temperature. High temperature and wide range operation make the cryocooler design more practical with sufficient margin. In collaboration with Aisin Seiki, our group at Tohoku University constructed a two stage Stirling cycle cryocooler, in which small lead balls of $0.1 \mathrm{~mm}$ in diameter were used for the coldest part of the regenerators. A front view of our machine and an enlarged view of the cold heads are shown in Fig.7. This cryocooler was built to test a design for compact, light weight, easy-tohandle refrigerators for eventual use in cooling cryogenic sensors. Measurements are now undertaken on cooling performance, mechanical vibration, temperature fluctuation, electromagnetic noise, etc. Specification are listed in Table 2. Expected cooling capacity is $50 \mathrm{~mW}$ at $15 \mathrm{~K}$. Although the tests with this trial machine have not been completed, a non-metalic structure and the use of heat pipe are now under consideration as a next step for reducing magnetic noise and temperature fluctuation respectively.

\section{MAGNETIC REFRIGERATION}

A study group on magnetic refrigeration was formed at the Society of Non-traditional Technology in 1980 to look into the possibility of its future use in refrigeration ranging from sub-room temperatures down to superfluid helium temperature $(21.8 \mathrm{~K})$. More recently, a group at the Tokyo Institute of Technology lead by Hashimoto and a group at Toshiba have cooperated in constructing a prototype machine aimed at establishing the feasibility of a magnetic refrigerator working between $20 \mathrm{~K}$ and $4.2 \mathrm{~K}$. The working substance used is Gadolinium Gallium Garnet (GGG) single crystal which has a relatively high entropy density, high heat conductivity and reasonably high Debye temperature $(\sim 500 \mathrm{~K})$. As the lattice entropy is small compared to the spin entropy below $20 \mathrm{~K}$ for GGG, the refrigerator may, in principle, be operated in a Carnot cycle. Heat of magnetization at the high temperature isothermal was removed by gaseous helium flowing through a pipe P (Fig.8). The lower end of GGG was attached to a thermosiphon, the cold end of the thermosiphon was used to condense helium gas. By measuring the rate of liquefication of helium, the refrigeration capacity at $4.2 \mathrm{~K}$ for a cycle starting at $16 \mathrm{~K}$ and $6.7 \mathrm{~T}$ using 1.7 mole of GGG was estimated to be $42 \mathrm{~J}$ when the field was reduced at a rate of $0.67 \mathrm{~T}$ per sec [7]. The magnetic field for this experiment was changed by energizing and de-energizing a superconducting pulse magnet at various sweep rates. This mode of altering the magnetic field is not favourable for practical use due to extra losses incurred in operation of the superconducting magnet. The experiment is still in its initial stage, however, and the method was used to investigate problems in the magnetic 
refrigeration cycle proper.

CONCLUSION

Groups engaged in $\mathrm{R} \& \mathrm{D}$ works on cryocoolers in Japan are summarized in Table 3. Almost all cryocooler activities are more or less stimulated by big national projects as pointed out in the introduction.

JNR invested more than 20 billion yen in the MAGLEV project and since 1979 the government has been subsidizing the project with an annual outlay of $600 \mathrm{milli}$ ion yen. However, the amount of the funds alloted to the refrigeration technology is not known.

Science and Technology Agency appropriated $463 \mathrm{million}$ yen in the 1982 fiscal year budget for promoting $R$ \& $D$ studies for establishing the technological base of applied superconductivity and cryogenics. Out of the total fund, about 95 million yen is to be alloted for refrigeration technology regarding Stirling cycle cryocoolers and magnetic refrigerators.

Ministry of Education and Culture supported university research on superconductive electronics with a grant of $600 \mathrm{million}$ yen for the period 1979 to 1981. Although the need for small cryocoolers gained gradual recognition in this area, development efforts are still minor.

Although basic research and digital application of superconductivity are in progress at various industries, Nippon Telegraph and Telephon Public Corporation, and Electrotechnical Laboratory. However, no explicit activities have not been reported on refrigeration at present.

The authors would like to thank Y. Kyotani for providing them with a mass of information on the JNR project. 
Table 1 Specifications of JNR MAGLEV On-Board Refrigerators

\begin{tabular}{|c|c|c|c|}
\hline Type & A & B & C \\
\hline Ref. Cycle & Claude & Claude & Stirling+J-T \\
\hline $\begin{array}{c}\text { Cooling Capacity at } \\
4.4 \mathrm{~K}(\mathrm{~W})\end{array}$ & 30 & 5 & 8 \\
\hline $\begin{array}{c}\text { lie Flow Rate } \\
(\mathrm{Nm} / \mathrm{h})\end{array}$ & 150 & 30 & 17.2 \\
\hline $\begin{array}{c}\text { Inlet Pressure } \\
\left(\mathrm{kg} / \mathrm{cm}^{2} \mathrm{G}\right)\end{array}$ & 15 & 16 & 18.9 \\
\hline $\begin{array}{c}\text { Size diam }(\mathrm{mm}) \\
\text { length (mm) }\end{array}$ & 1400 & 300 & 296 \\
\hline Weight (Kg) & 140 & 800 & 33.9 \\
\hline
\end{tabular}

Table 2 Specifications of the Cryocooler Built in Tohoku University to Test a Design for Eventual Use in Cooling Cryogenic Sensors.

\begin{tabular}{|c|c|}
\hline Item & Specification \\
\hline Refrigeration Cycle & Stirling cycle \\
\hline Output (cooling capacity) & $50 \mathrm{~mW}$ at $15 \mathrm{~K}$ \\
\hline Lowest temperature & $\sim 10 \mathrm{~K}$ \\
\hline Working gas & Helium \\
\hline Input power & $150 W$ \\
\hline Dimension & $260 \mathrm{~mm} \times 290 \mathrm{~mm} \times 540 \mathrm{~mm}$ \\
\hline Weight & $24 \mathrm{Kg}$ \\
\hline Drive & $\lesssim 5 \mathrm{~Hz}$ \\
\hline
\end{tabular}


Table 3 List of Groups Working with Cryocoolers in Japan

\begin{tabular}{|c|c|c|c|}
\hline Group & Leader & Object & $\begin{array}{l}\text { Refrigeration } \\
\text { Cycle }\end{array}$ \\
\hline Aisin Seiki Co. Ltd. & T. Tani & $\begin{array}{l}\text { Mag. Lev. } \\
\text { Cryopump } \\
\text { SQUID }\end{array}$ & $\begin{array}{l}\text { Stirling }+J-T \\
\text { Stirling } \\
\text { Stirling }\end{array}$ \\
\hline Consultant & Y. Ishizaki & $\begin{array}{l}\text { Mag. Lev. } \\
\text { Josephson Com- } \\
\text { puter } \\
\text { Cryopump }\end{array}$ & $\begin{array}{l}\text { Stirling Cycle } \\
\text { Machine } \\
\text { Cryogenic System }\end{array}$ \\
\hline Hitachi Ltd. & T. Fujinaga & Mag. Lev. & Claude \\
\hline JNR & Y. Kyotani & Mag. Lev. & $\begin{array}{l}\text { Stirling } \\
G-M+J-T \\
\text { Claude }\end{array}$ \\
\hline $\begin{array}{l}\text { Mitsubishi Electric } \\
\text { Corporation }\end{array}$ & Y. Furuta & Mag. Lev. & $\mathrm{G}-\mathrm{M}+\mathrm{J}-\mathrm{T}$ \\
\hline $\begin{array}{l}\text { Sumitomo Heavy } \\
\text { Industries, Ltd. }\end{array}$ & T. Koizumi & Mag. Lev. & Claude \\
\hline Toshiba Corporation & $\begin{array}{l}\text { M. Yamaji } \\
\text { H. Nakagome }\end{array}$ & $\begin{array}{l}\text { Mag. Lev. } \\
\text { Superfluid }{ }^{4} \mathrm{He}\end{array}$ & $\begin{array}{l}\text { Claude } \\
\text { Magnetic Refri- } \\
\text { rator }\end{array}$ \\
\hline Nihon University & Y. Mat subara & $\begin{array}{l}\text { Study of } \\
\text { Regenerator }\end{array}$ & $\begin{array}{l}\text { Regenerative } \\
\text { Cycle }\end{array}$ \\
\hline Tohoku University & $\begin{array}{l}\text { T. Ohtsuka } \\
\text { T. Fujita }\end{array}$ & SQUID & Stirling \\
\hline $\begin{array}{l}\text { Tokyo Institute of } \\
\text { Technology }\end{array}$ & T. Hashimoto & Superfluid ${ }^{4} \mathrm{He}$ & $\begin{array}{l}\text { Magnetic Refri- } \\
\text { gerator }\end{array}$ \\
\hline
\end{tabular}




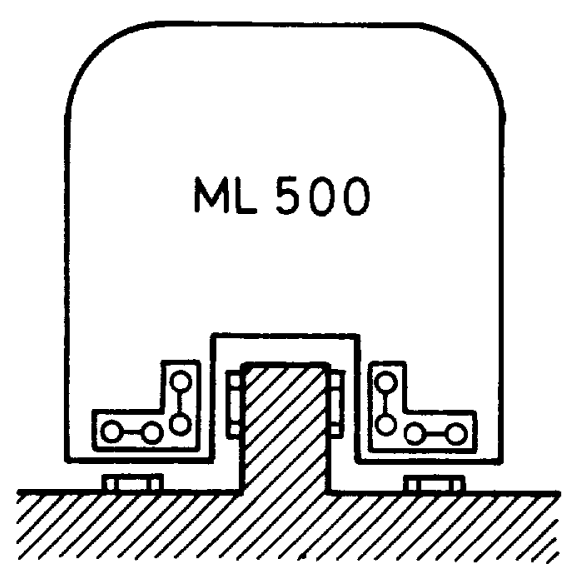

(a)

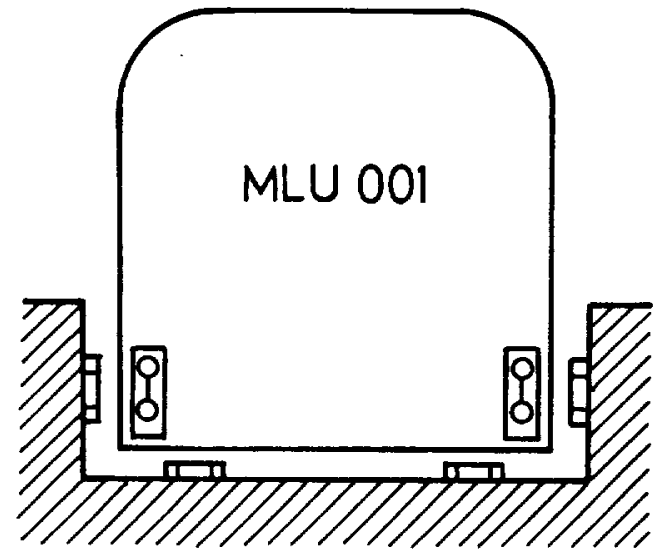

(b)

Figure 1. Schematic views of (a) ML500 on the inverted Tshaped guideway and (b) MLU001 on the U-shaped guideway. The vehicles carry liquid helium cryostat systems of L-shape and $I$-shape respectively.

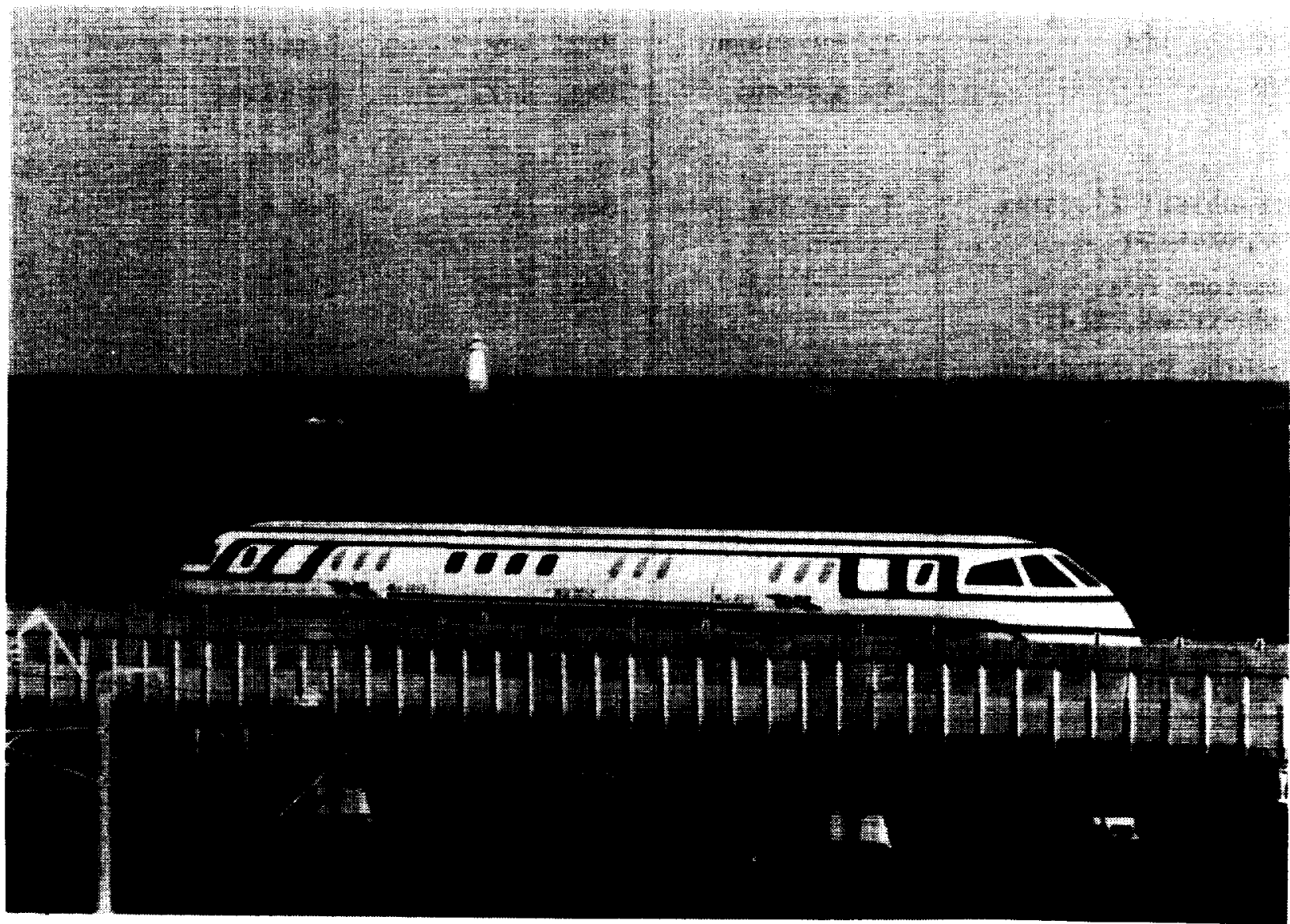

Figure 2. Photograph of MLU001 running on the test track. 

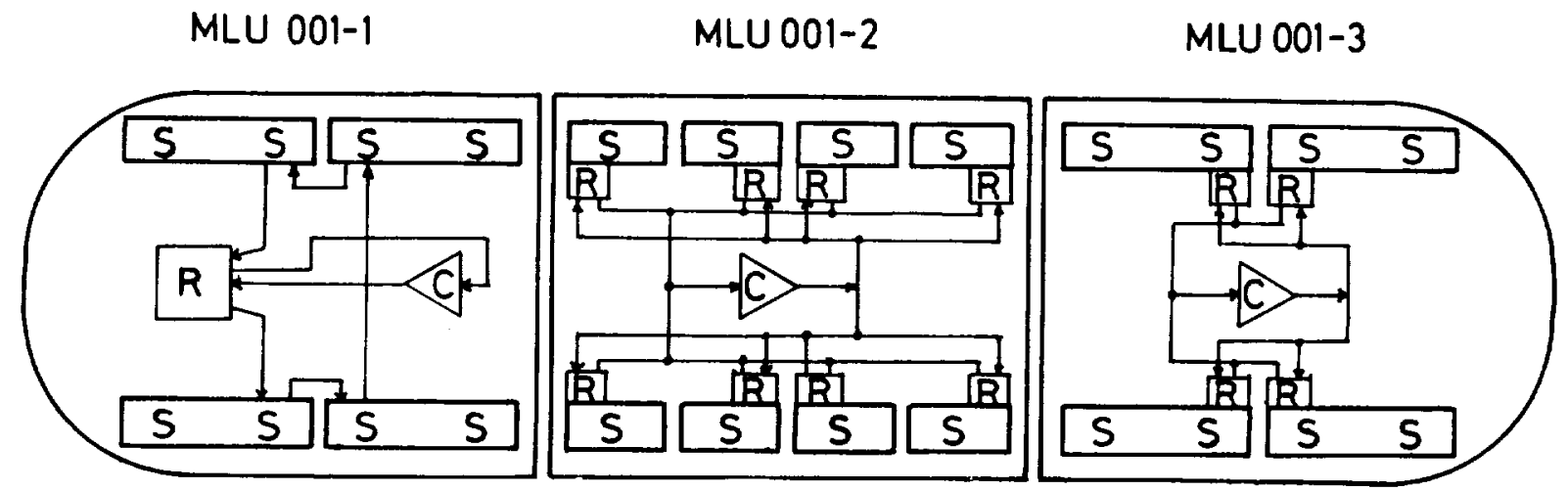

Figure 3. Schematic diagram of the eryogenic system on MLU001. S : Superconducting magnet, $\mathrm{R}$ : Refrigerator, $\mathrm{C}$ : Compressor.

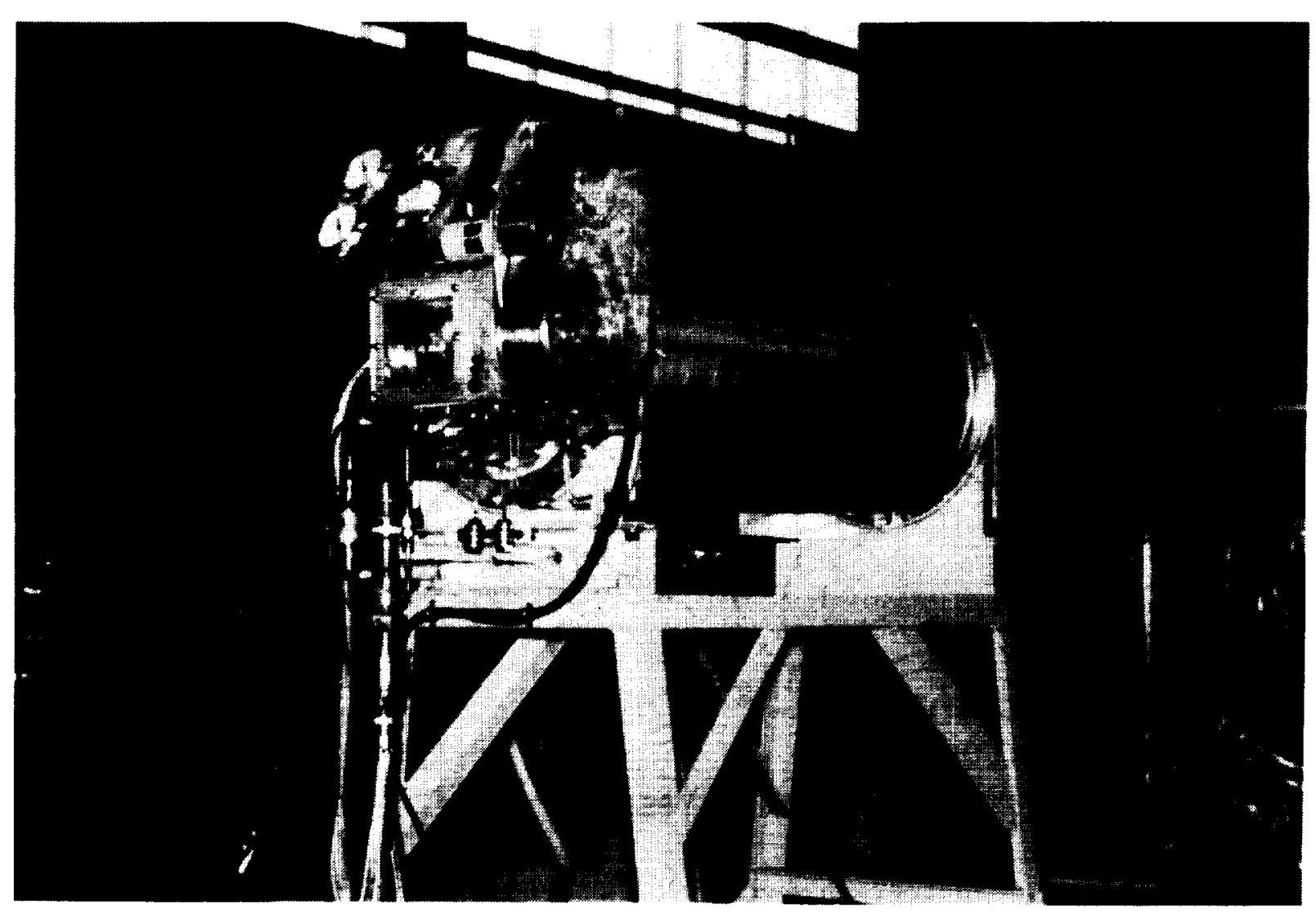

Figure 4. A Claude cycle on-board refrigerator of type A. 

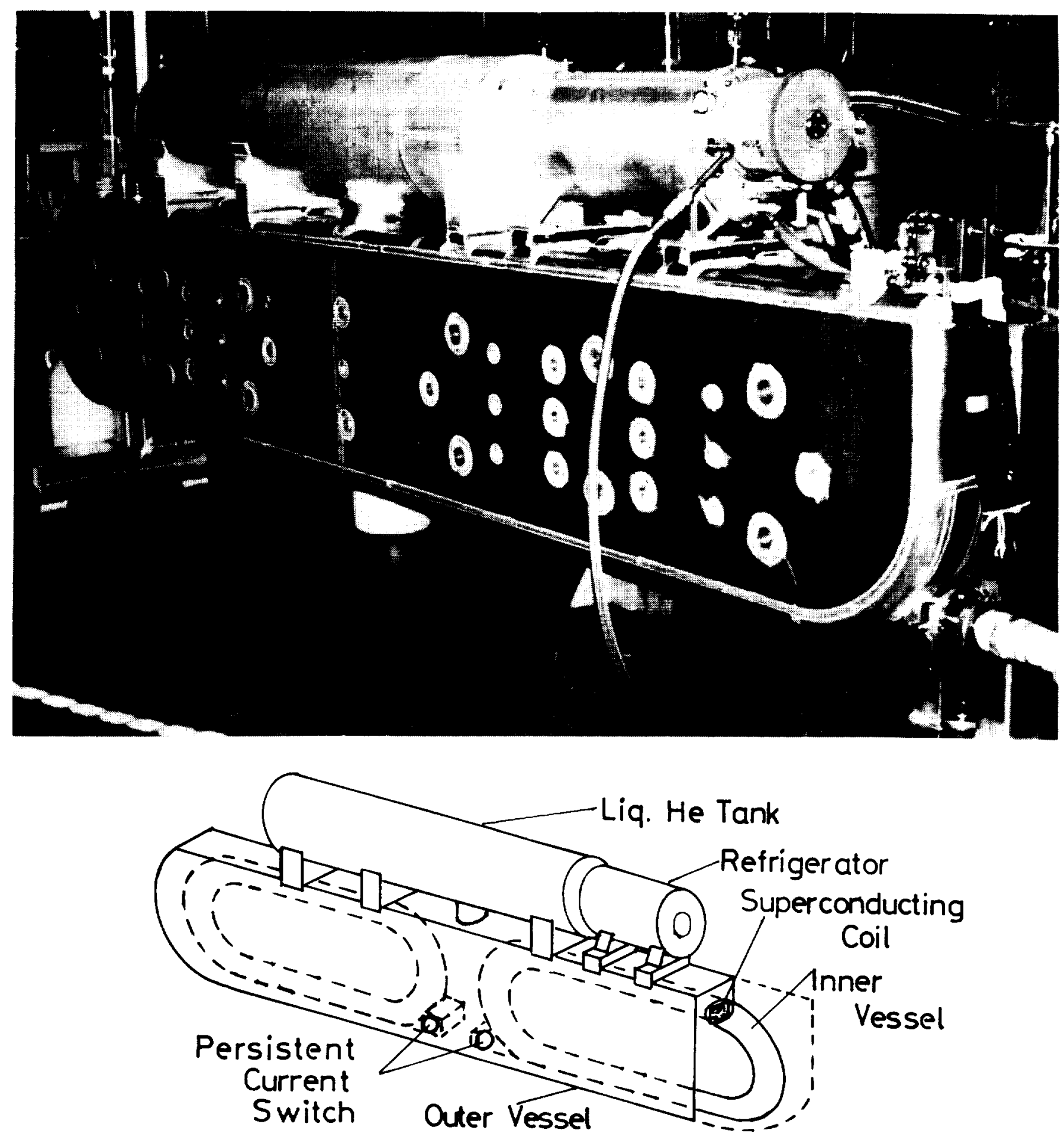

Figure 5. Photograph (upper) of an on-board refrigerator mounted on the I-shaped cryostat system. The structure is outlined in the schematic drawing (lower). 


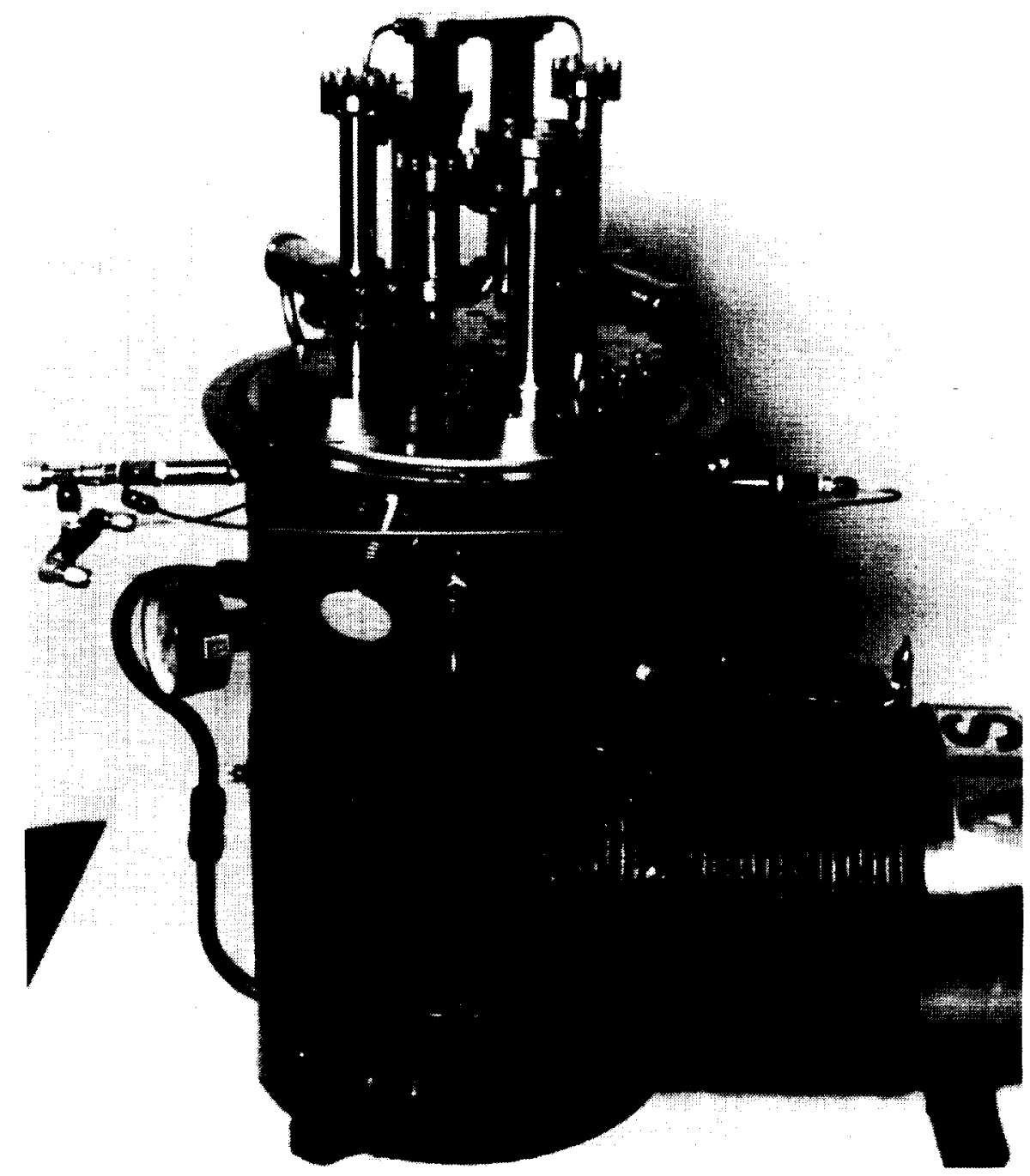

Figure 6. A 2-stage Stirling cycle cryocooler commercially developed for general purposes. 


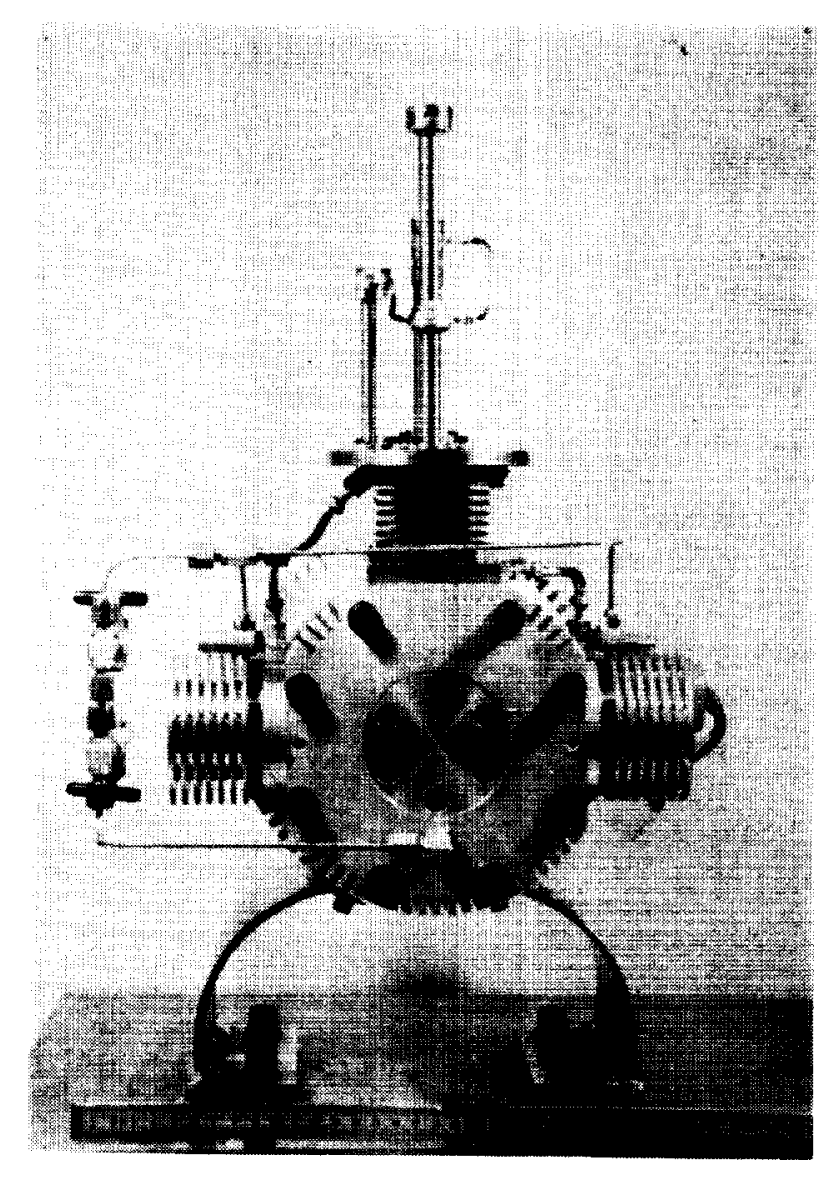

(a)

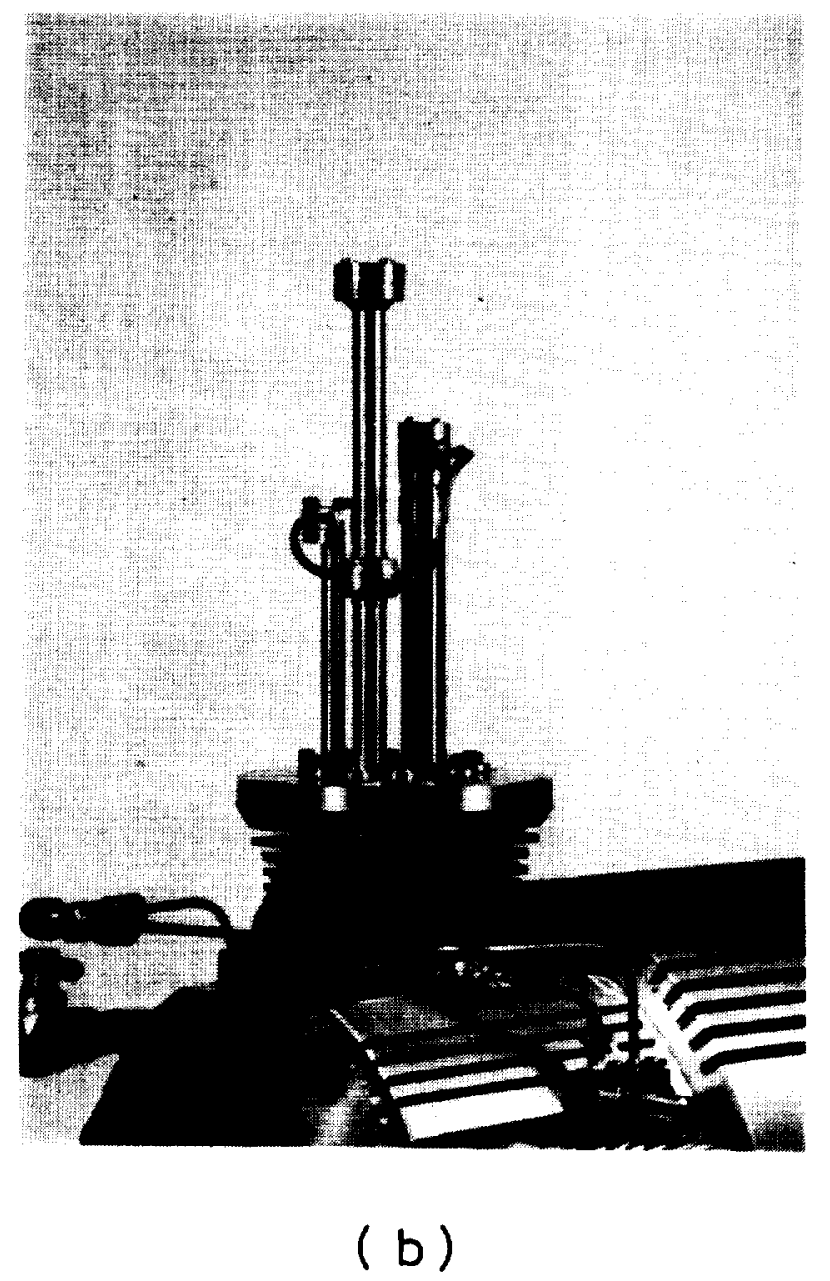

(b)

Figure 7. A test model of low-power Stirling cycle cryocooler for SQUID sensors: (a) front view and (b) cold head 


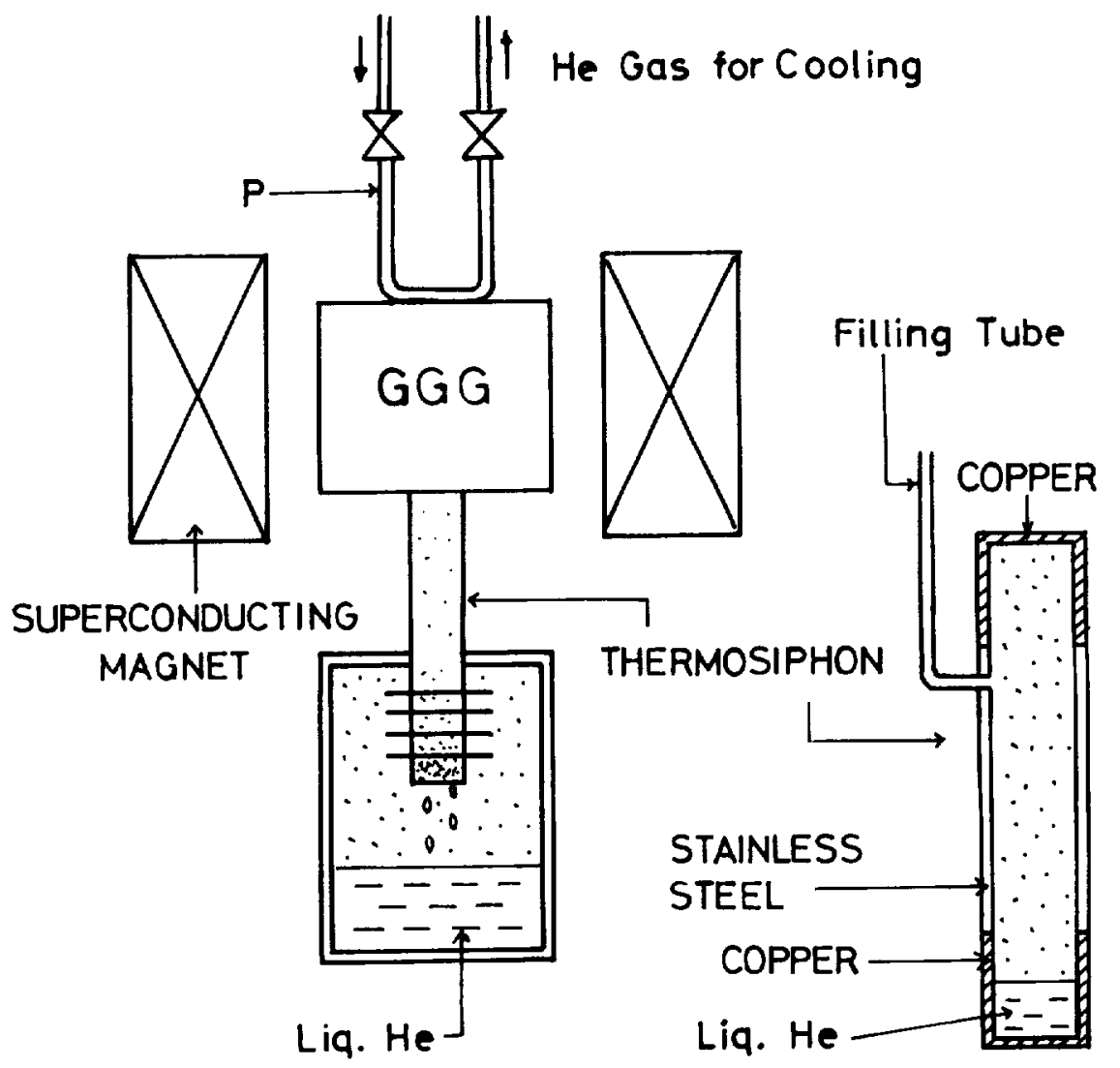

Figure 8. Schematic arrangement of experiments on magnetic refrigeration 


\section{REFERENCES}

[1] Matsubara, Y. and Yasukochi, K.: An Application of Gap Regenerator/ Expander Precooled by Two State G-M Refrigerator (This Conference).

[2] Oshima, K. and Ishizaki, Y.: Refrigeration Technology in Japan, Proc. 5th International Cryogenic Engineering Conference, Kyoto, edited by K. Mendelssohn, IPC Science and Technology Press (1974) pp.357-360.

[3] Ishizaki, Y., Kuroda, T. and Ohtsuka, T.: Sealed Cryostat System for Magnetically Levitated Vehicles, ibid., pp.102-105.

[4] Ohtsuka, T. and Kyotani Y.: Recent Progress in Superconducting Magnetic Levitation Tests in Japan, IAS Conference Record, CH1575-0/80/0000-0238, IEEE (1980) pp.238-243.

[5] Koizumi, T., Kanazawa, M., Takahashi, M., Uchida, T. and Suzuki, M.: A Small and Light Weight Heat Exchanger for On-Board Helium Refrigerator (This Conference).

[6] Fujita, T., Suzuki, M., Ikegawa S., Ohtsuka, T. and Anayama, T.: High Temperature Operation of $\mathrm{Nb}_{3} \mathrm{Ge}$ SQUIDs, Proc. 9th International Cryogenic Engineering Conference, Kobe, edited by K. Yasukochi and H. Nagano, Butterworth \& Co. (1982) pp369-372.

[7] Hashimoto, T.: private communication. 